\title{
La Unión de Rabassaires y las respuestas de los viticultores catalanes frente a la crisis vinícola de comienzos del siglo $\mathrm{XX}^{*}$
}

\author{
Jordi Planas ${ }^{1}$ \\ Universitat de Barcelona \\ j.planas@ub.edu
}

RESUMEN: Durante el primer tercio del siglo XX, el sector vitícola se vió sumido en una grave crisis, como resultado de una sobreproducción estructural a escala internacional. Este artículo centra su atención en las vías de acción colectiva de los viticultores catalanes como respuesta a la crisis y, en especial, en la Unión de Rabassaires que, desde su creación en 1922, fue la principal organización sindical agraria de Cataluña y una de las más importantes de España. Se analizan las relaciones entre la Unión de Rabassaires y la Unión de Viticultores de Cataluña, una organización que pretendia agrupar al conjunto de los viticultores, destacando sus coincidencias y divergencias en su lucha contra la crisis vinícola. También se analizan las relaciones de la Unión de Rabassaires con el cooperativismo vitivinícola, que en Cataluña se hallaba en expansión a comienzos de los años veinte, y se explican las razones de su desarrollo muy independiente del sindicalismo rabassaire.

PALABRAS CLAVE: Unión de Rabassaires; acción colectiva; sector vinícola; bodegas cooperativas; Cataluña; siglo XX.

* Este trabajo ha contado con la ayuda de los proyectos de investigación subvencionados por el Ministerio de Economía y Competitividad (RTI2018-093970-B-C33) y por la Generalitat de Cataluña (2017 SGR 1466). Una versión muy preliminar fue presentada al seminario «Rabassa morta y rabassaires (siglos XVIII-XX)», celebrado en la Universidad de Barcelona el 26-27 de enero de 2017. Agradezco los comentarios de los asistentes al seminario, así como las observaciones y sugerencias de Samuel Garrido, Raimon Soler y de los evaluadores anónimos de esta revista.

1 ORCID iD: https://orcid.org/0000-0002-9155-0870.

Copyright: (C) 2020 CSIC. Este es un artículo de acceso abierto distribuido bajo los términos de una licencia de uso y distribución Creative Commons Reconocimiento 4.0 Internacional (CC-BY 4.0) 
The Union of Rabassaires and the Catalan winegrowers response to the twentieth-century wine sector crisis

ABSTRACT: During the first third of the twentieth century, the wine sector was plunged into serious crisis, as a result of structural overproduction on an international scale. This article focuses on the collective action of Catalan winegrowers in response to the crisis and, especially, the Union of Rabassaires, which, since its creation in 1922, was the main agricultural trade union organization in Catalonia and one of the most important in Spain. The article analyses the relations between the Union of Rabassaires and the Union of Winegrowers of Catalonia, an organization that sought to group all winegrowers together, highlighting their coincidences and divergences to combat the wine crisis. It also analyses the relations between the Union of Rabassaires and the winemaking cooperatives, which were expanding in Catalonia in the early nineteen twenties, and explains the reasons why their development was completely independent of Rabassaire unionism.

KEY WORDS: Union of Rabassaires; collective action; wine sector; winemaking cooperatives; Catalonia; twentieth century.

CÓMO CITAR ESTE ARTÍCULO/CITATION: Planas, Jordi, «La Unión de Rabassaires y las respuestas de los viticultores catalanes frente a la crisis vinícola de comienzos del siglo XX», Hispania, 80/264 (Madrid, 2020): 201-229. https://doi.org/10.3989/hispania.2020.007.

\section{INTRODUCCIÓN}

Durante el primer tercio del siglo XX, el sector vitícola catalán se vió sumido en una grave crisis. Después de la plaga filoxérica, que en las dos últimas décadas del siglo XIX destruyó por completo la viña en Cataluña, el vino no recuperó los precios tan remunerativos que había tenido en el período anterior; al contrario, a lo largo del primer tercio del siglo XX experimentaron una clara tendencia depresiva, con fuertes caídas en los años 1905-10, 1920-25 y 1930-35, como resultado de una sobreproducción estructural a escala internacional ${ }^{2}$.

Los viticultores respondieron a la crisis del sector con tres vías distintas de acción colectiva. Una primer respuesta fue la movilización de protesta que desde 1911 encauzó la Unión de Viticultores de Cataluña (UVC). Esta asociación seguía el ejemplo de la Confédération Générale des Vignerons, una gran organización de viticultores que se había creado en el Midi francés en 1907, después de una campaña de masivas protestas por la caída de los precios del vino ${ }^{3}$. Se

\footnotetext{
2 PINILLA y AYUDA, 6 (2002): 51-85. SIMPSON, 2011: 30-76. PAN-MONTOJO, 1994: 315-373; 9/18 (2009). PUJOL, 1986: 317-346. COLOMÉ et al., 281 (2013): 29-55.

${ }^{3}$ ROCHE-AGUSSOL, 1924. LACHIVER, 1988: 461-471. GAVIGNAUD-FONTAINE, 1997.
}

Hispania, 2020, vol. LXXX, n. ${ }^{\circ} 264$, enero-abril, págs. 201-229, ISSN: 0018-2141, e-ISSN: 1988-8368 
trataba de una movilización corporativa del conjunto de los viticultores, que hacían un frente común para reclamar la intervención del Gobierno en la regulación del mercado vinícola y, especialmente, en la persecución del fraude en la producción de vino ${ }^{4}$.

Otra respuesta fue la creación de cooperativas. Con la creación de bodegas y destilerías cooperativas, los viticultores intentaban adaptarse a las nuevas condiciones de los mercados, reduciendo costes de producción, mejorando la calidad del vino (para remunerarlo mejor), aprovechando los subproductos y mejorando su posición negociadora en la comercialización del producto. Sus resultados fueron desiguales, por las exigencias (técnicas, financieras y de gobernanza) de este tipo de cooperativas, aunque en Cataluña tuvieron un desarrollo notable, especialmente en las comarcas de Tarragona ${ }^{5}$.

Una tercera respuesta fue el sindicalismo rabassaire. Los rabassaires eran arrendatarios de tierras cedidas por el propietario para que el rabassaire las plantara de viñas y las cultivara a su costa, por un tiempo indefinido vinculado a la vida de las cepas (al que alude la denominación del contrato de rabassa morta), a cambio del pago de una parte de la cosecha. Aunque después de la filoxera los contratos perdieron su carácter enfitéutico original, los rabassaires seguían considerándose propietarios de las viñas (puesto que en la mayoría de los casos las replantaron ellos mismos) y continuaron su lucha para mejorar sus condiciones contractuales y redimirse del pago de la renta de la tierra ${ }^{6}$. La caída de los precios del vino después de la replantación de la viña no hizo más que agudizar el conflicto secular entre propietarios y rabassaires, puesto que para muchos rabassaires la venta del vino constituía su principal ingreso.

Durante el primer tercio del siglo XX, los rabassaires utilizaron la lucha sindical y política para conseguir una redistribución de la renta de la tierra ${ }^{7}$. El sindicato Unión de Rabassaires (UR), que fue la organización más duradera y de mayor implantación de toda la historia de este movimiento social, se creó en 1922 en este contexto depresivo del sector vitivinícola, y tuvo su máxima expansión en los años treinta, cuando la crisis vinícola se agudizó, en un contexto de proteccionismo y cierre de los mercados, así como también la conflictividad social agraria.

Estas tres vías de acción colectiva no fueron en modo alguno compartimentos estancos. Aunque de naturaleza distinta, constituían respuestas sociales a

\footnotetext{
${ }^{4}$ PLANAS, 35/2 (2017): 175-206.

5 SIMPSON, 1 (2000): 95-126. SAUMELL, 2002. PLANAS, 58/2 (2016): 264-282. FERNÁNDEZ y SIMPSON, 70/1 (2017): 122-142. GARRIDO, 2019.

${ }^{6}$ Sobre la problemática vinculada al contrato de rabassa morta, además de los trabajos seminales de GIRALT, 3 (1964): 51-72 y BALCELLS, 1968, véase CARMONA y SIMPSON, 59/2 (1999a): 290-315; 38 (1999b): 105-124. COLOMÉ, 67 (2013): 115-140. GARRIDO, 70/3 (2017a): 977-1003; 107 (2017b): 155-182; 35/3 (2017c): 415-443. MORENO, 78 (2019): 7-36.

7 POMÉS, 2000. COLOMÉ et al., 63/1 (2018): 1-27. SOLER-BECERRO, 2019.
} 
una problemática que afectaba al conjunto del sector vitivinícola, y que podían actuar de forma complementaria. Por consiguiente, a menudo compartían protagonistas. Sin embargo, como veremos, el desarrollo de una de las vías de acción colectiva también podía suponer restricciones o bloqueos en otras. Esto es lo que pretende observar este artículo, analizando las relaciones entre la UR, la UVC y el cooperativismo vitivinícola.

Después de la introducción, en el segundo apartado se explica la posición de la UR frente a la crisis vinícola y sus diferencias con la UVC. El tercer apartado aborda la posición de la UR ante el desarrollo del cooperativismo vitivinícola, que se hallaba en expansión en Cataluña a comienzos de los años veinte, al mismo tiempo que se organizaba el sindicalismo rabassaire. Finalmente, el último apartado se refiere a los cambios que se producen en los años treinta en la estrategia de la UR en relación con el cooperativismo vitivinícola y sus límites. Una breve conclusión pone punto final al artículo.

\section{«LA DESCONFIANZA QUE NOS INSPIRA LA UNIÓN DE VITICULTORES DE Cataluña»}

Como había sucedido en Francia, el malestar provocado por los precios poco remunerativos del vino en sucesivas cosechas $(1905,1907,1908,1909)$, dio lugar a una amplia movilización de los viticultores catalanes para protestar por esta situación y demandar soluciones al Gobierno español. Fruto de esta movilización fue la creación, en 1911, de la UVC, que en pocos meses estableció delegaciones en más de doscientas localidades de Cataluña y llegó a contar con unos veinte mil adheridos ${ }^{8}$, una cifra que el sindicato UR no llegaría a superar hasta los años treinta. Un observador cualificado como Jaume Raventós daba cuenta de la expansión formidable de esta organización: «No sé si jamás se ha visto en el movimiento agrícola de nuestro país surgir una sociedad con más rapidez, con más empuje, con más vigor que ésta» ${ }^{9}$.

En aquel momento el movimiento rabassaire estaba relativamente desorganizado. Después de la agitación de fines del siglo XIX, la represión gubernamental, por un lado, y la necesidad de nuevos pactos para replantar las viñas, por el otro, habían disminuído la capacidad organizativa de los rabassaires. Hay que añadir aquí las iniciativas asociativas de carácter interclasista que, en este contexto, impulsaron los propietarios. En 1899 el Instituto Agrícola Catalán de San Isidro (IACSI) había creado la Federación Agrícola Catalana —desde 1902 Federación Agrícola Catalano-Balear (FACB) - , que durante las dos primeras décadas del siglo XX agrupó a más de un centenar de cámaras y

\footnotetext{
${ }^{8}$ Revista IACSI, Barcelona, 20.11.1911.

9 Revista IACSI, 5.5.1911.
} 
sindicatos agrícolas, entidades de carácter mixto, compuestas de propietarios y cultivadores agrícolas que, indirectamente, quedaron bajo la órbita de la gran asociación de los propietarios rurales catalanes ${ }^{10}$.

La crisis vinícola fue una preocupación constante en las reuniones de la FACB desde sus inicios y la creación en su seno de la UVC fue resultado de sus campañas. Su objetivo era agrupar al conjunto del sector vitivinícola y, efectivamente, entre sus miembros había grandes y pequeños viticultores; pero su dirección estuvo siempre en manos de los grandes propietarios vitícolas ${ }^{11}$. Para éstos, la creación de una gran asociación interclasista era la vía para evitar la conflictividad social:

En la gran família vinyatera hi entre tothom, del gran hisendat al jornaler; sols l'acció fraternitzant d'una lliga amplíssima pot ofegar [...] la revolta injusta del petit contra'l de dalt o la opressió també injusta d'aquest al que té sota seu ${ }^{12}$.

La UVC intentó conseguir la aplicación de medidas que revalorizaran los precios del vino, especialmente a través de la lucha contra el fraude en la elaboración de los vinos y contra los impuestos que disminuían su consumo. El bajo precio del vino era lo que, desde la perspectiva de sus dirigentes, constituía el problema fundamental del sector. Su iniciativa fue seguida en Navarra y, después, también en la Rioja y otras regiones vitícolas españolas; pero no fue hasta 1924 cuando consiguió fundarse la Confederación Nacional de Viticultores (CNV), lo que es indicativo de las dificultades para organizar al conjunto de los viticultores españoles y presionar al Gobierno español en defensa de sus intereses. La creación de la UR y sus diferencias estratégicas con la UVC, que lideraba la movilización de los viticultores españoles, no podían sino debilitar sus demandas de regulación del sector vinícola, que contaban, además, con una fuerte oposición de las organizaciones de comerciantes y exportadores de vino ${ }^{13}$.

A diferencia de la UVC, los rabassaires luchaban para conseguir un cambio en las condiciones contractuales que redujera sustancialmente la renta que tenían que pagar al propietario, o bien la eliminara totalmente accediendo a la propiedad de la tierra. La estrategia de la UVC, en cambio, pretendía reducir la caída de los ingresos de los viticultores con un aumento del precio del vino y no a través de la redistribución de la renta de la tierra. Uno de los máximos propagandistas de la UVC, el reverendo de Sant Sadurní d'Anoia Josep Maria Rovira, lo sintetizaba con estas palabras:

\footnotetext{
10 PLANAS, 2006: 107-116.

11 Como la FACB, la UVC tenía su local social en la sede del IACSI. No fue hasta 1919 que trasladó su domicilio social a una sede independiente (Revista IACSI, 5.2.1919).

${ }^{12}$ Gazeta de la Conca, Montblanc, 8.6.1911. Citado en MAYAYO, 1995: 83.

${ }^{13}$ FERNÁNDEZ, 45 (2008): 113-141. PLANAS, 35/2 (2017): 175-206.
} 
I és que la verdadera solució del problema, des del punt de vista econòmic, no està sols en collir cinquanta o cent cargues de vi, sinó en que aquestes siguin venudes a un preu remunerador. Si aquest pagès, suposat sempre el tracte just, fent una pressió, fent una vaga, una resistència mancomunada amb els demés companys, logra saltar per sobre la justícia del pacte i obté que la terra que cultiva a mitjes sigui al terç o la que és al terç sigui al quart, si només ha obtingut això, no ha obtingut cap millora econòmica ${ }^{14}$.

Aunque este enfoque del problema tendía a disolver el conflicto de clases entre propietarios y rabassaires, a estos últimos la caída de los precios del vino también les perjudicaba y, por tanto, las campañas para revalorizar los precios del vino tampoco podían resultarles ajenas de ningún modo. Desde la UR surgieron algunas iniciativas en esta misma dirección desde prácticamente sus inicios. Al término de su primer congreso, que reunió a unos tres mil trabajadores agrícolas en el Teatro Marina de Barcelona el 6 de enero de 1923, una comisión se entrevistó con el gobernador civil de Barcelona y le hizo entrega de las conclusiones, todas relativas a la situación contractual de los rabassaires. Aprovechó entonces para solicitar medidas contra la adulteración y falsificación de los vinos, y a las conclusiones entregadas se añadió una conclusión adicional, que también fue entregada al gobernador civil, para insistir en la necesidad de favorecer la exportación de vinos españoles y de «solucionar el problema que plantea a toda la producción vinícola nacional $»^{15}$.

En la asamblea de delegados que la UR celebró el año siguiente, la crisis vinícola también fue objeto de debate, cuando una sección pidió que se añadiera a las conclusiones aprobadas la necesidad de perseguir el fraude en los vinos y de que el Gobierno pusiera freno a «la escandalosa libertad de utilizar alcohol industrial en las bebidas alcohólicas». Estas eran peticiones que formaban parte del programa de la UVC y la defensa de la proposición se basó, precisamente, en que «la Unión de Viticultores no responde a las necesidades de los campesinos y, por tanto, es necesario que los rabassaires sean quienes lleven a cabo esta campaña» ${ }^{16}$. La propuesta fue aprobada, después de la defensa que realizó Fèlix Duran Cañameras, argumentando que no era incompatible formar parte de la UR y al mismo tiempo de la UVC. Sin embargo, este dirigente rabassaire acabó por abandonar la UR aquel mismo año ante la disconformidad expresada por el Comité directivo en pleno con «la orientación excesivamente personal que daba a su actuación»». Unos

${ }^{14}$ El Baix Panadés, El Vendrell, 24.4.1920. Citado en SAUMELL, 2002: 42.

${ }^{15}$ La Terra, Barcelona, 15.1.1923. Casi al mismo tiempo, una comisión de la UVC también había visitado al gobernador civil de Barcelona para interesarse por la persecución del fraude en el vino.

${ }^{16}$ La Terra, 12.1.1924.

${ }_{17}$ La Terra, 12.7.1924.

Hispania, 2020, vol. LXXX, n. ${ }^{\circ} 264$, enero-abril, págs. 201-229, ISSN: 0018-2141, e-ISSN: 1988-8368 
meses más tarde, la UR también expulsaría a Joan Bonastre, otro de los dirigentes que había encabezado la línea más receptiva a las propuestas de la $\mathrm{UVC}^{18}$. En 1931, ambos dirigentes impulsaron la creación de una Federación de Rabassaires alternativa a la UR, que no llegó a consolidarse ${ }^{19}$.

El órgano de prensa de la UR (La Terra) prestaba apoyo a las campañas de la UVC, pero advertía que ello no significaba que la UR compartiera sus criterios, y desestimaba una acción común entre ambas organizaciones, con el argumento de que los planteamientos de la UVC olvidaban la cuestión esencial, que era el encarecimiento del precio de coste del vino a causa de las partes del fruto que tenían que pagar al propietario, y que no podían ser compañeros de causa «el que vive ociosamente y el que trabaja» ${ }^{20}$.

Aunque la UVC no era considerada un adversario directo de la UR, como lo era el IACSI, tampoco se establecía con ella «una corriente de simpatía demasiado patente $)^{21}$. Desde la UR se atribuía la pérdida de apoyos que la UVC había experimentado desde sus inicios a su falta de atención al problema social agrario. En efecto, después de una expansión fulgurante, en qué la UVC llegó a contar con unos veinte mil adheridos, este número fue reduciéndose progresivamente $^{22}$. Según los dirigentes de la UR, el retroceso se debía a que los rabassaires se habían dado cuenta de quiénes les explotaban y que, mientras los contratos de cultivo no cambiaran, «sabe[n] que hay que luchar en los propios organismos y que es necesario anteponer el problema social a muchos otros problemas de interés más secundario $\rangle^{23}$. Admitían, por tanto, que una parte de los rabassaires había secundado las campañas de la UVC, y algunos lo seguían haciendo si nos atenemos a las apelaciones que La Terra les dirigía para que se opusieran a la reelección de Francesc Santacana como presidente de la UVC ${ }^{24}$. Inversamente, desde el punto de vista de la UVC las diferencias entre propietarios y cultivadores de viña debilitaban la defensa de los intereses del conjunto de los viticultores, $y$, en los años treinta, llegaron a atribuir el fracaso del

${ }^{18}$ La petición de medidas contra la adulteración y falsificación de vinos que la UR trasladó al gobernador civil de Barcelona después de su primera asamblea fue una iniciativa de Joan Bonastre.

19 SOLER-BECERRO, 2019: 170.

${ }^{20}$ La Terra, 25.8.1923.

${ }^{21}$ La Terra, 31.5.1924.

22 Según la memoria anual presentada en la VI Asamblea de la UVC, celebrada en Igualada en abril de 1917, el número de socios de la organización era de 15.000 (Boletín de la Cámara Agrícola Oficial de Igualada y su Comarca, Año VII, 151, abril 1917). En 1924 aún constaban oficialmente 17.237 socios (MUÑIZ, 1924: 176); pero en 1933, según el censo oficial de sindicatos agrícoles, la UVC contaba ya sólo con 3.412 miembros (Boletín Oficial de la provinca de Barcelona, 1.7.1933).

${ }^{23}$ La Terra, 24.5.1924.

${ }^{24}$ La Terra, 2.2.1924. 
Estatuto del Vino y la caída de los precios del vino a la prioridad que se otorgaba a la cuestión social agraria ${ }^{25}$.

De todos modos, los dirigentes de la UR eran conscientes de que si no querían verse relegados en estas cuestiones por los «actuales usurpadores de la representación de la agricultura $»^{26}$ - refiriéndose a la UVC—, tenían que afrontar no sólo el problema social agrario sino también el problema económico del conjunto de la vitivinicultura. En consecuencia, en relación a las campañas que realizaba la UVC frente a la crisis vinícola, se pronunciaban públicamente y defendían su punto de vista, que en algunos aspectos era coincidente y en otros claramente divergía. Por ejemplo, en 1924 la UVC se declaró partidaria de ensayar otros cultivos y dar una mayor importancia a la uva de mesa, además de otras medidas para reducir la producción vinícola. Naturalmente, la UR se manifestó absolutamente contraria a la reducción de la superfície vitícola, una propuesta que colisionaba frontalmente con la defensa de los derechos de los rabassaires, que se fundamentaban precisamente en las cepas plantadas, e insistió en la supresión de la renta del propietario ${ }^{27}$.

En el informe enviado a la Conferencia Nacional Vinícola celebrada en 1930, la UR se sumó a las peticiones de la UVC para la supresión de los arbitrios municipales sobre el vino, la prohibición del encabezado de los vinos, las guías de cosecha y otras iniciativas para limitar el fraude y favorecer el consumo vinícola. En cambio, se mostró partidaria de la libertad de exportación de vinos y en contra de la limitación de plantar viña, en clara divergencia con la posición defendida por la UVC. Al mismo tiempo, insistía en el problema que «representa para el cultivador la renta que exige el propietario de la tierra y la amenaza que supone para la propiedad del cultivador ${ }^{28}$.

Los dirigentes de la UR temían que las soluciones económicas que proponía la UVC desviaran la atención de la cuestión social, que ellos consideraban el problema fundamental del campesinado. La falta de receptividad de los dirigentes rabassaires a las propuestas de la UVC se fue modulando con el tiempo, pero en octubre de 1933 su secretario general aún se refería despreciativamente a la revalorización de los precios agrarios como un «cúralo-todo» que pretendía relegar los cambios legislativos en favor de los menos favorecidos, y añadía que «no importa tanto vender caro como saber la parte del producto que corresponderá al productor $»^{29}$, en claro antagonismo con la posición de la UVC.

Esta diferencia de estrategias también fue un obstáculo para la confluencia entre el movimiento rabassaire y el cooperativismo vitivinícola, con el cual la

\footnotetext{
${ }^{25}$ Pagesia, Barcelona, 22.9.1934.

${ }^{26}$ La Terra, 1.3.1924.

${ }^{27}$ La Terra, 31.5.1924.

${ }^{28}$ La Terra, 12.7.1930.

29 La Humanitat, Barcelona, 29.10.1933.
} 
UVC estaba íntimamente conectada. Como se ha señalado, la UVC fue creada en el marco de la FACB, una organización que agrupaba las cooperativas agrícolas que se habían fundado en Cataluña y las Baleares bajo la forma de cámaras y sindicatos agrícolas. Además, sus principales dirigentes provenían del ámbito del cooperativismo ${ }^{30}$, y en sus campañas no perdía la oportunidad de animar a sus adheridos a crear bodegas y destilerías cooperativas. Esta interrelación entre la UVC y el cooperativismo vitivinícola puede explicarse, en primer lugar, por el objetivo común de afrontar la crisis vinícola; pero, además, porque las cooperativas reforzaban las campañas de la UVC, convirtiéndose en una caja de resonancia para sus iniciativas y en una red relacional más estable de lo que permitía la participación puntual de los adheridos a la UVC en los mítines y en los congresos anuales de la organización. La UVC seguía aquí también una estrategia similar a la de la Confédération Générale des Vignerons en Francia ${ }^{31}$.

En la tercera asamblea de la UVC, celebrada en Falset (1914), se aprobó una propuesta a las Cortes para el «fomento de los Sindicatos agrícolas cooperativas de elaboración y venta, a) subvencionándolos, b) concediéndoles préstamos hipotecarios», así como la creación de una sección administrativa especial dentro de la UVC «para facilitar datos y tramitar expedientes relativos a las cooperativas de alcohol vínico y de elaboración y venta de vinos $\rangle\rangle^{32}$. En la asamblea celebrada en Igualada (1917), se amplió el acuerdo adoptado en Falset con la autorización a los consejos comarcales de la UVC para subvencionar con un préstamo la creación de destilerías cooperativas de ámbito comarcal ${ }^{33}$. Dos años después, en la asamblea de Martorell (1919), se insistió de nuevo en «fomentar la creación de las Bodegas Cooperativas y procurar una federación entre los Sindicatos comarcales, para, con los sobrantes de Caja, establecer depósitos de exportación y venta, y crear un cuerpo de corredores para los mercados extranjeros $\rangle^{34}$.

Un paso más en esta estrategia fue la decisión tomada en la asamblea de Montblanc (1921) de convertir la UVC en «Confederación de las Federaciones

${ }^{30}$ Por poner sólo un par de ejemplos: Josep M. Barnadas, fundador y secretario general de la UVC, era el secretario (desde su fundación en 1906 hasta 1939) del Sindicato Alella Vinícola, una de las primeras y más exitosas cooperativas vinícolas; por su parte, Francesc Santacana, que fue presidente (1918-26) y máximo líder de la UVC, fue también el fundador y presidente (191732) del Sindicato Vitícola Comarcal de Martorell, la mayor destilería cooperativa que se creó en Cataluña y que se convirtió en el modelo a seguir para las que se crearon después.

${ }^{31}$ CAUPERT, 1921: 111. ROCHE-AGUSSOL, 1924: 46-48. PLANAS, 35/2 (2017): 175-206.

32 Revista IACSI, 5.5.1914. La UVC tomaba como modelo la protección que el Estado francés dispensaba en ese país a los sindicatos agrícolas (Resumen de Agricultura, Barcelona, 5.1914).

${ }^{33}$ Revista IACSI, 20.4.1917.

${ }^{34}$ Revista IACSI, 20.5.1919.

Hispania, 2020, vol. LXXX, n. ${ }^{\circ}$ 264, enero-abril, págs. 201-229, ISSN: 0018-2141, e-ISSN: 1988-8368 https://doi.org/10.3989/hispania.2020.007 
Vitícolas catalanas, fomentando por todos los medios posibles la creación de Sindicatos Agrícolas vitícolas por todas las tierras de Cataluña ${ }^{35}$. Estos sindicatos agrícolas tenían que agruparse en federaciones comarcales que, además de defender los intereses vitícolas, promoverían la creación de destilerías cooperativas, siguiendo el modelo de la Federación Agrícola de la Conca de Barberà, creada en 1916 y que agrupaba una veintena de cooperativas vitivinícolas de esta comarca ${ }^{36}$. Durante estos años, la UVC desarrolló una intensa campaña para la creación de bodegas cooperativas en distintas localidades vitícolas catalanas, con mítines en los que participaban sus principales dirigentes, y, en 1921, instaló en su sede un muestrario de vinos de distintas clases que elaboraban las bodegas cooperativas catalanas ${ }^{37}$.

La vinculación de la UVC con el cooperativismo vitivinícola se hizo más necesaria a medida que las demandas de regulación del mercado vinícola ante el Gobierno español no alcanzaban los resultados esperados. En 1925 la UVC aún contaba con unos 18.000 adheridos $^{38}$, pero la organización estaba en crisis y se llegaba a especular con su disolución ${ }^{39}$, una posibilidad que dos años más tarde admitía públicamente su presidente ${ }^{40}$.

Fue entonces cuando un grupo de cooperativas, lideradas por la Federación Agrícola de la Conca de Barberà, impulsó la reorganización de la UVC como confederación de cooperativas, con la convicción de que además de la elaboración del vino, era necesario movilizarse para conseguir un incremento de los precios de venta del producto ${ }^{41}$. Con la adhesión de la Federación Agrícola de la Conca de Barberà y de otras 27 cooperativas agrícolas ${ }^{42}$, la UVC se transformó efectivamente en confederación de cooperativas e, incluso, comenzó a operar como cooperativa de segundo grado con la compra de insumos agrícolas como azufre, sulfato de cobre y fertilizantes químicos ${ }^{43}$.

Sin embargo, en 1930 la Federación Agrícola de la Conca de Barberà tomó la decisión de separarse de la UVC y adherirse directamente a la CNV, con el

${ }^{35}$ Revista IACSI, 6.1921.

${ }^{36}$ Sobre esta federación, véase PLANAS y VALLÈS, 2015: 456-468.

${ }^{37}$ Revista IACSI, 20.10.1920 y 5.11.1920. Agricultura, Barcelona, 20.11.1920, 5.1.1921 y 5.3.1921.

${ }^{38}$ Agricultura, 20.3.1925.

${ }^{39}$ Agricultura, 20.6.1925.

${ }^{40}$ La U.V.C, Barcelona, 15.2.1927.

${ }^{41}$ Además de la Federación Agrícola de la Conca de Barberà y de la propia UVC, impulsaron esta inciativa la Federación Agrícola del Alt Camp de Tarragona, la Cámara Agrícola de Falset, los sindicatos agrícolas del Vendrell, Barberà y Montblanc, y la bodega cooperativa de Barberà de la Conca (Agricultura, 20.12.1926).

${ }^{42}$ La U.V.C., 8.2.1927.

43 En 1929, los ingresos por ventas de insumos sumaban 181.599 pesetas, mientras que las cuotas de socios sólo importaban 10.503. (La U.V.C., junio de 1930). 
objetivo de «trabajar más intensamente y con más posibilidades de éxito» ${ }^{44}$, lo que indica que los problemas que arrastraba la UVC no habían desaparecido con su transformación en confederación de cooperativas. Aun así, cuando un año después se creó la Unión de Sindicatos Agrícolas de Cataluña (USAC), la UVC se constituyó en su comité de producción vinícola, como veremos más adelante.

\section{LA UNIÓN DE RABASSAIRES Y EL COOPERATIVISMO VITIVINÍCOLA}

Cuando en 1922 se constituyó la UR, el cooperativismo vitivinícola se encontraba en Cataluña en plena expansión. Había entonces en funcionamiento unas sesenta bodegas cooperativas —más de la mitad construidas en los tres años anteriores - y también se habían creado las destilerías cooperativas más importantes: Martorell (1917), l'Arboç (1919), l'Espluga de Francolí (1919), Vilajuïga (1921) y Reus (1922). En el contexto español era un movimiento cooperativo totalmente excepcional, puesto que, contando apenas con el $20 \%$ de la superfície de viña y el $30 \%$ de la producción de vino, se localizaban en Cataluña un $70 \%$ de las bodegas cooperativas ${ }^{45}$.

Aunque algunas de las primeras bodegas cooperativas surgieron por iniciativa de los pequeños viticultores y en algunas localidades se crearon dos bodegas cooperativas (la de «los ricos» y la de «los pobres»), la gran mayoría fueron promovidas por viticultores acomodados, o bien contaron con el apoyo de algún propietario con recursos ${ }^{46}$. Una de las razones que permite explicarlo se encuentra en las exigencias de financiación (para la construcción y equipamiento de la bodega) y de gestión (conocimientos técnicos y administrativos) de este tipo de cooperativas, que no estaban fácilmente al alcance de los rabassaires, en su mayoría muy pequeños productores y sin apenas tierra en propiedad. La inseguridad de su situación contractual también dificultaba su participación en unas entidades que exigían un compromiso de permanencia y una mayor disciplina organizativa que otras cooperativas.

$\mathrm{Si}$, además, los rabassaires no querían someterse a la tutela de los propietarios, que tenían mayores facilidades para conseguir financiación para el proyecto cooperativo, las posibilidades para participar en estas cooperativas disminuían y, como hemos visto, los dirigentes de la UR se oponían a las asociaciones mixtas o interclasistas. La mayoría de bodegas cooperativas se creaban como secciones

${ }^{44}$ Aires de la Conca, Montblanc, 3.5.1930.

45 PLANAS, 2015: 369-401; 58/2 (2016): 264-282.

${ }^{46}$ MAYAYO, 5 (1985): 133-155. GAVALDÀ y SANTESMASES, 1993. FUGUET y MAYAYO, 1994. PAN-MONTOJO, 1994: 360-362. SANTESMASES, 1996. PLANAS, 2015: 369-401. 
vinícolas de cooperativas preexistentes, de modo que la orientación «de clase» que ambicionaban para las bodegas cooperativas era aún más difícil de conseguir. Además, el apoyo técnico y en algunos casos financiero que las bodegas cooperativas recibían de la Mancomunitat de Cataluña, que estaba en manos del regionalismo conservador, despertaba enormes recelos entre los dirigentes rabassaires. De hecho, la UR llegó a considerar «perturbadora» la intervención de la Mancomunitat en el pleito rabassaire ${ }^{47}$.

¿Qué actitud adoptar frente a la expansión del cooperativismo vitivinícola? La UR se encontraba en un difícil dilema, puesto que sus dirigentes eran conscientes de los beneficios económicos que para los rabassaires podía comportar su participación en las bodegas cooperativas; pero, al mismo tiempo, se oponían al asociacionismo interclasista y sabían que las bodegas cooperativas «han sido en su mayor parte dirigidas por gente propietaria y este es uno de los desaciertos capitales del agrarismo catalán $\rangle^{48}$. Desde la UR se exhortaba a los trabajadores agrícolas a alejarse de todas las cooperativas participadas por propietarios rentistas y a asociarse a la UR como «la única entidad constituida en Cataluña e incluso en España en la cual no existen estas confusiones ${ }^{49}$.

Algunos dirigentes de la UR se manifestaban abiertamente favorables al cooperativismo vitivinícola. Por ejemplo, Pere Esmendia, que fue uno de los primeros secretarios del Comité Central de la UR y redactor en jefe de La Terra, se declaraba «partidario acérrimo» de establecer bodegas cooperativas en cada localidad, convencido de que la elaboración individual del vino era un sistema totalmente anticuado. Aún así, no podía evitar referirse a las interferencias de los propietarios en el desarrollo del cooperativismo vitivinícola, lamentando que en algunas localidades los viticultores hubieran sido engañados por los caciques y sus ilusiones frustradas por «desvergonzadas ambiciones o politiquerías de campanario» ${ }^{50}$. Estos recelos frenaban la adhesión de los dirigentes rabassaires al cooperativismo vitivinícola, aunque sabían que tarde o temprano tendrían que tomar una actitud y que, obedeciendo al espíritu moderno y reformador de la UR, habría que aconsejar a sus asociados que participaran en las cooperativas para conseguir «el máximo rendimiento de sus productos con el mínimo gasto posible $)^{51}$.

En cualquier caso, la UR no fue capaz de impulsar un modelo de bodega cooperativa «de clase», como pretendía. Si observamos la distribución de las bodegas cooperativas en Cataluña a mediados de los años veinte y la comparamos con la implantación que tenía entonces la UR (mapa 1), observamos una manifiesta desconexión entre ambos fenómenos.

\footnotetext{
${ }^{47}$ La Terra, 26.1.1924.

${ }^{48}$ La Terra, 3.11.1923.

49 Agricultura i Ramaderia, Barcelona, 15.6.1928.

50 Pere Esmendia, «Els cellers cooperatius», La Terra, 16.2.1924.

${ }^{51}$ P., «Vinificació individual i vinificació colectiva», La Terra, 13.10.1923.
} 
MAPA 1. Bodegas cooperativas existentes en 1925 y municipios con sociedades y secciones locales de la UR

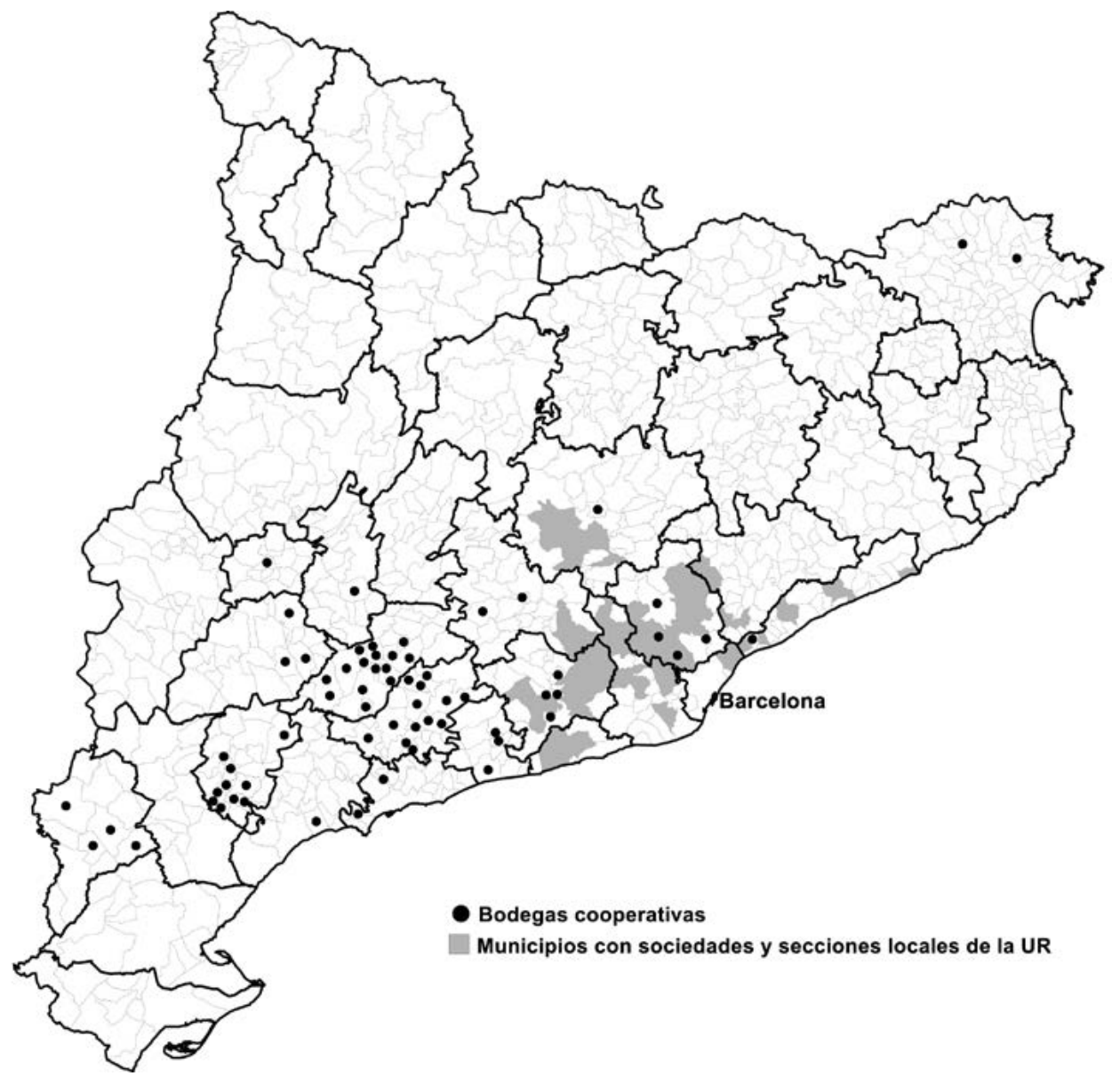

Fuentes: PLANAS, 2015: 393 (bodegas cooperativas) y COLOMÉ et al., 63/1 (2018): 1-27 (municipios con sociedades y secciones locales de la UR).

La mayoría de bodegas cooperativas estaban localizadas en la provincia de Tarragona, donde en sus inicios la UR no tenía implantación. Como puede verse en el mapa 1, del total de bodegas cooperativas que había entonces en funcionamiento (67), sólo dos — las de Rubí y Sant Cugat del Vallès- se encontraban en localidades donde existía una sociedad adherida a la UR, y estas dos bodegas cooperativas, como veremos a continuación, tuvieron un desarrollo completamente independiente del sindicalismo rabassaire. 
La bodega cooperativa de Rubí se creó en 1919 como sección de la cámara agrícola local, que agrupaba a los principales propietarios rurales de la localidad y que no desarrollaba actividades cooperativas sino recreativas y políticas. La cámara agrícola rivalizaba políticamente con el Centro Democrático Republicano, que fue precisamente la asociación que cobijó al sindicalismo rabassaire local en sus inicios. Las orientaciones políticas de la cámara agrícola - primero vinculadas con el cacique local de Terrassa, Alfonso Sala Argemí, y después con la Lliga Regionalista - eran tan manifiestas que, inicialment, los fundadores de la bodega cooperativa - «con el objetivo de disipar el recelo» ${ }^{52}$, según confesó el primer vicepresidente de la bodega cooperativa a la prensa local - intentaron evitar vincularse a ella. Sin embargo, las dificultades que encontraron para poner en marcha la bodega cooperativa acabaron por aconsejarles que se constituyera al amparo de la cámara agrícola, y no fue hasta los años treinta cuando la bodega cooperativa se desvinculó de ella.

¿Cuál fue la participación del colectivo rabassaire en esta bodega cooperativa? El cuadro 1 intenta responder a esta pregunta a partir de la comparación nominal de los socios de la bodega cooperativa y de los adheridos a la Sociedad de Rabassaires de Rubí en los años treinta, cuando ambas entidades tenían una adhesión más numerosa. En esta comparación, pues, la pertenencia al colectivo rabassaire se basa no en la situación contractual de cada campesino, sino en su militancia en la Sociedad de Rabassaires. La bodega cooperativa de Rubí, que inició su actividad con 119 socios, en 1934 ya contaba con un total de 175 asociados, que constituían «casi la mitad de los viticultores de la localidad»" $»^{53}$. Disponemos de una relación nominal de los socios de la bodega cooperativa en el año 1931 (un total de 171), así como de todas las juntas directivas desde su fundación hasta 1936. Un total de 49 socios de la bodega cooperativa (29\%) constaban en el Censo de Cultivadores de 1936 (que incluía un total de 317 individuos), y sólo 2 socios (1,2\%) constaban en el Censo de Propietarios de 1936 (que incluía sólo 18 individuos). Aunque el Censo de Propietarios era, sin duda, incompleto, el predominio de los pequeños campesinos entre los socios de la cooperativa es evidente. Hay que señalar, sin embargo, que uno de los dos propietarios identificados fue uno de sus fundadores y que ocupó los cargos más importantes en su junta directiva: fue el tesorero en la primera junta directiva (1920), después ocupó la presidencia (1921-22) y más tarde ejerció de nuevo como tesorero (1926-31 y 1942-43) ${ }^{54}$.

En 1936, un 26\% de los socios de la bodega cooperativa eran miembros de la Sociedad de Rabassaires de Rubí, que contaba entonces con 310 adheridos.

${ }^{52}$ Saba Nova, Rubí, 22.2.1920.

53 «Rubí i l’agricultura», Endavant, Rubí, 31.12.1933.

${ }^{54}$ En un informe de la Junta Municipal Agraria de 1938 era considerado un faccioso y se le identificaba políticamente con la Lliga Catalana y también con la USAC (Junta Municipal Agraria de Rubí, acta de la reunión del 23.3.1938, Archivo Municipal de Rubí). 
De estos últimos, en 1931 sólo un 15\% formaba parte de la bodega cooperativa. Por tanto, aunque efectivamente algunos miembros de la Sociedad de Rabassaires eran socios de la cooperativa, las coincidencias entre ambas asociaciones fueron muy limitadas. Esta conclusión se reafirma cuando nos fijamos en los dirigentes de ambas entidades: sólo ocho (menos del 5\%) de los que ocuparon cargos en la junta directiva de la bodega cooperativa entre 1920 y 1936 - y uno solo de sus principales dirigentes - se adhirieron a la Sociedad de Rabassaires. La relación inversa (dirigentes de la Sociedad de Rabassaires que en 1931 fueran socios de la bodega cooperativa) es más difícil de establecer con precisión, puesto que de la Sociedad de Rabassaires no disponemos de todos los cuadros dirigentes del período examinado. Sin embargo, los datos disponibles apuntan a una presencia también anecdótica: sólo dos casos (1\%).

CUADro 1. Participación del colectivo rabassaire en la base social de la bodega cooperativa de Rubí

\begin{tabular}{|l|r|r|}
\hline & $\begin{array}{r}\text { Socios } \\
\mathbf{( 1 9 3 1 )}\end{array}$ & \multicolumn{1}{c|}{} \\
\hline Cultivadores (censo 1936) & 49 & 28,7 \\
\hline Propietarios (censo 1936) & 2 & 1,2 \\
\hline Miembros de la Sociedad de Rabassaires de Rubí (1936) & 45 & 26,3 \\
\hline Dirigentes de la bodega cooperativa & 40 & 23,4 \\
\hline $\begin{array}{l}\text { Dirigentes de la bodega cooperativa miembros de la de } \\
\text { Rabassaires }\end{array}$ & 8 & 4,7 \\
\hline Principales dirigentes de la bodega cooperativa* & 18 & 10,5 \\
\hline $\begin{array}{l}\text { Principales dirigentes de la bodega cooperativa miembros de la Sociedad } \\
\text { de Rabassaires* }\end{array}$ & 1 & 0,6 \\
\hline Total socios de la bodega cooperativa de Rubí & 171 & 100,0 \\
\hline
\end{tabular}

* Los principales cargos considerados son: presidente, vicepresidente, secretario y tesorero.

Fuentes: Relación de socios del Sindicato Agricola «Celler Cooperatiu» de Rubí, 1931; Relación de juntas directivas del «Celler Cooperatiu» de Rubi, 1920-1988; Relación de socios de la Sociedad de Rabassaires de Rubi, 5.6.1936; Censo de Cultivadores de Rubi, 29.4.1936; y Censo de Propietarios de Rubi, 29.4.1936. Todo en el Archivo Municipal de Rubí.

La bodega cooperativa de Sant Cugat del Vallès se creó en 1921 por iniciativa de un grupo de grandes propietarios vitícolas que contaron con la ayuda de los Servicios Técnicos de la Mancomunitat. Su fundación vino precedida de un 
acto de propaganda en el que participaron el director del Servicio de Acción Social Agraria de la Mancomunitat y algunos de los principales dirigentes de la UVC ${ }^{55}$. Los técnicos del Servicio de Viticultura y Enología de la Mancomunitat intervinieron en la redacción de sus estatutos, así como en el proceso de vinificación una vez la bodega cooperativa empezó a funcionar. Los promotores de la iniciativa ya habían fundado un sindicato agrícola local en 1906. Uno de ellos, propietario de una de las mayores fincas rústicas del municipio y miembro del IACSI, propuso ya en 1912 la creación de una bodega cooperativa, pero entonces no tuvo éxito. Cuando, en 1921, se creó el sindicato vitícola que impulsó la construcción de la bodega cooperativa fue elegido presidente por aclamación. Sin embargo, dimitió poco después a causa de los problemas que tenía entonces con los rabassaires que trabajaban en sus tierras, los cuales se negaban a ingresar en la bodega cooperativa ${ }^{56}$. Como resultado de las desaveniencias con los rabassaires, los propietarios que habían promovido la creación de la cooperativa acabaron por abandonarla, quedando ésta en una situación financiera muy comprometida.

Aunque la cooperativa superó estos contratiempos, estos hechos son indicativos de los problemas que tenían que afrontar estas entidades como consecuencia de las diferencias entre propietarios y rabassaires. Es difícil estimar el impacto del sindicalismo rabassaire sobre la difusión del cooperativismo vitivinícola, pero resulta altamente revelador observar el escaso número de bodegas cooperativas creadas durante el primer tercio del siglo XX en aquellas comarcas barcelonesas donde la UR tenía su mayor implantación: Alt Penedès (4), Anoia (2), Bages (3), Vallès Occidental (4), Baix Llobregat (0).

Esto ya había llamado la atención al antropólogo Edward Hansen, quien advertía que, a diferencia de lo ocurrido en la provincia de Tarragona, en la comarca del Alt Penedès «el cooperativismo [vitivinícola] no empezó a desarrollarse hasta el período de la dictadura de Primo de Rivera, y aún entonces sólo en cuatro localidades; además, en ninguna de ellas se crearon dos cooperativas, la de los pequeños campesinos y la de los propietarios $\rangle^{57}$. Antoni Saumell también afirmaba que la única vía de cooperativismo vitivinícola que arraigó en el Penedès fue «el modelo interclasista avalado desde la agricultura 'de orden', las instituciones oficiales [en referencia a la Mancomunitat] y la Iglesia ${ }^{58}$. Según este autor, una de las causas de la debilidad del cooperativismo vitivinícola en el Penedès eran las suspicacias ideológicas que despertaba entre los rabassaires el caràcter conservador de las bodegas cooperativas.

\footnotetext{
55 Agricultura, 20.11.1920.

56 TROYANO, 9 (1996): 79-100.

57 HANSEN, 42/3 (1969): 232.

58 SAUMELL, 2003: 279.
} 
Como resultado de una distribución de la tierra muy desigual ${ }^{59}$, las tensiones sociales entre propietarios y rabassaires dificultaban la colaboración necesaria para proyectos de envergadura como eran las bodegas cooperativas. Es posible que algunos propietarios vieran en las cooperativas un instrumento para apaciguar las tensiones sociales; sin embargo, una conflictividad elevada desanimaba las iniciativas de colaboración conjunta, o bien, en algunos casos, incentivaba la creación de entidades rivales ${ }^{60}$. Por esta razón, en el Penedès los propietarios apostaron por la «vía individual» de modernización del sector vitivinícola y no a través del cooperativismo vitivinícola ${ }^{61}$.

La desigualdad y la conflictividad social también inducía a los rabassaires a buscar en el sindicalismo reivindicativo la mejora de su situación social y, por tanto, a evitar someterse a la tutela de los propietarios en las cooperativas interclasistas que ellos impulsaban. Las fórmulas asociativas que los rabassaires desarrollaron de forma autónoma en el ámbito local tenían un carácter multifuncional, donde el cooperativismo agrícola y de consumo se combinaba con el mutualismo, las funciones recreativas y las propiamente sindicales y políticas $^{62}$. Pero difícilmente podían disponer de los recursos financieros necesarios para construir una bodega cooperativa.

En las bodegas cooperativas, por contra, se intentaba evitar toda confrontación entre propietarios y rabassaires para no provocar divisiones internas y la desafección de una parte de los socios. En consecuencia, incluso aquellas bodegas cooperativas que habían sido fundadas por iniciativa de los pequeños campesinos evitaban a toda costa un alineamiento con la UR. La bodega cooperativa de Igualada, fundada por viticultores vinculados al republicanismo local, evitó adherirse a la UR incluso una vez iniciada la Guerra Civil. Ya en 1931 su presidente rechazó una propuesta para que el secretario general de la UR pronunciara una conferencia «para no incluir el Sindicato en cuestiones agrarias que podrían perjudicar la marcha progresiva del mismo» ${ }^{63}$. En cambio, desde 1923, la bodega cooperativa era miembro activo de la UVC y en 1931 entró a formar parte de la USAC.

El Sindicato Agrícola del Vendrell, que creó una de las primeras y más importantes bodegas cooperativas del Penedès, también se vinculó desde sus inicios a la UVC y se adhirió a ella como socio colectivo, «en vista del abandono en que está sumida la viticultura y por ser la Unión de Viticultores de

59 SOLER-BECERRO, 2019.

${ }^{60}$ PLANAS Y VALLS-JUNYENT, 7/2 (2011): 310-321.

${ }^{61}$ SAUMELL, 2002.

${ }^{62}$ MAYAYO, 5 (1985): 133-155; 1989: 209-232. GAVALDÀ, 1989. LÓPEZ ESTUDILLO, 1989: 191-207. SANTESMASES, 1996. POMÉS, 2000. PLANAS y VALLS-JUNYENT, 7/2 (2011): 310-321. SOLER-BECERRO, 2019; en prensa.

${ }_{63}$ Acta de la junta directiva del Sindicato de Viticultores de Igualada, 11.9.1931. Citada en PLANAS, 2013: 271.

Hispania, 2020, vol. LXXX, n. ${ }^{\circ}$ 264, enero-abril, págs. 201-229, ISSN: 0018-2141, e-ISSN: 1988-8368 https://doi.org/10.3989/hispania.2020.007 
MAPA 2. Bodegas cooperativas existentes en 1933 y municipios con sociedades y secciones locales de la UR

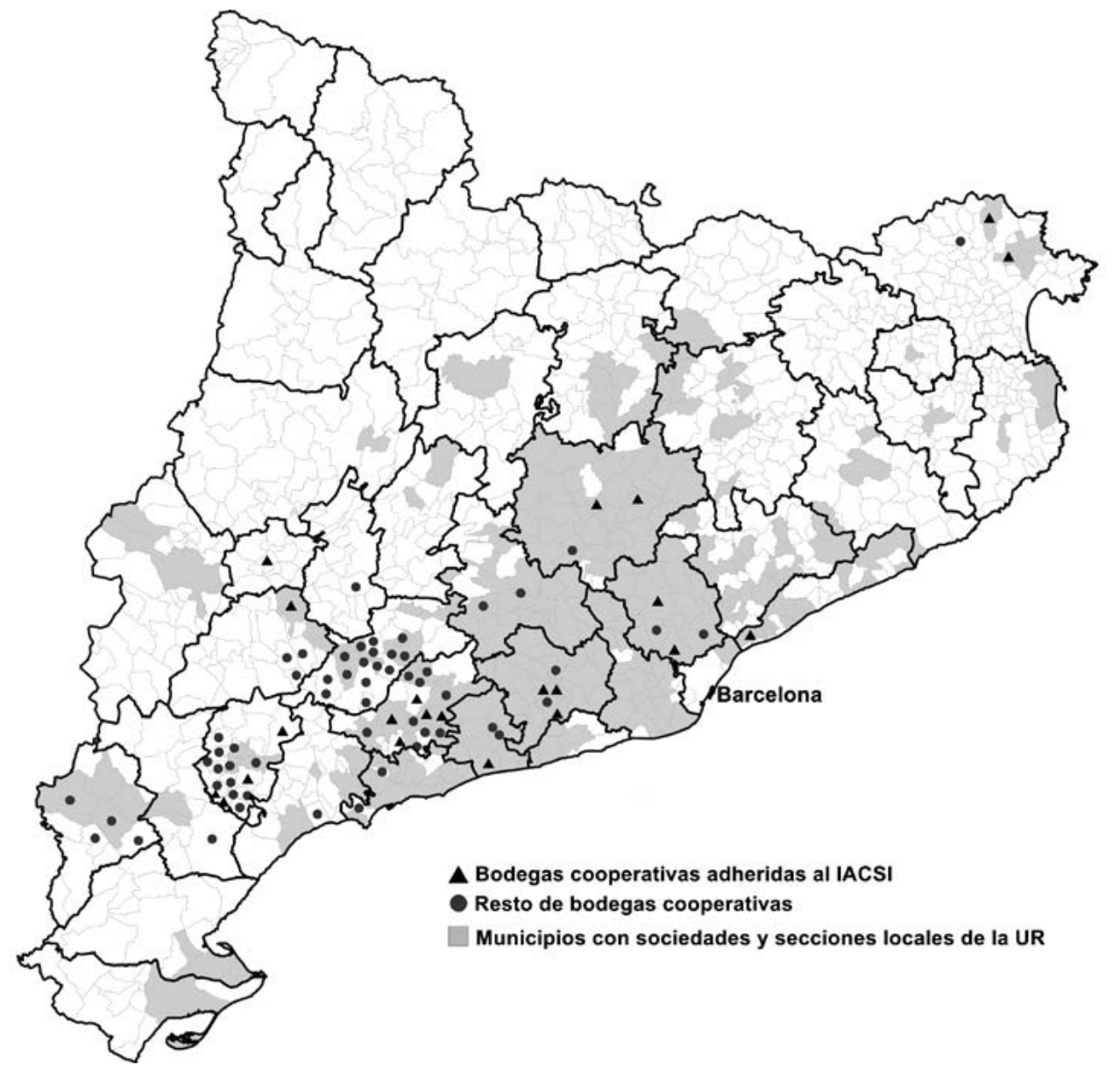

Fuentes: PLANAS, 2015: 393 (bodegas cooperativas), PLANAS, 2006: 263-270 (asociaciones adheridas al IACSI) y COLOMÉ et al., 63/1 (2018): 1-27 (municipios con sociedades y secciones locales de la UR).

Cataluña la más genuina y auténtica defensora del campesinado ${ }^{64}$. Para una organización interclasista, el alineamiento con la UVC se juzgaba más neutro y menos comprometido que el que podían establecer con organizaciones «de clase» como la UR o el IACSI. Sin embargo, en 1929 el Sindicato Agrícola del

${ }^{64}$ Acta de la junta directiva del Sindicato Agrícola del Vendrell, 27.1.1924. Citada en SAUMELL, 1998: 537. 
Vendrell también solicitó su ingreso como socio colectivo del IACSI, vinculándose directamente con la organización que agrupaba a los grandes propietarios rurales catalanes.

No fue en modo alguno un caso aislado. Desde finales de los años veinte un número apreciable de entidades que tenían entre sus secciones una bodega cooperativa se inscribieron como socios colectivos del IACSI, haciendo, pues, evidente su alineamiento «de clase» con la organización representativa de los propietarios rurales. En cambio, hasta los años treinta la UR no tuvo la adhesión de ninguna bodega cooperativa, y aún en estos años, cuando la UR contaba en sus filas con más de trescientos sindicatos agrícolas, las bodegas cooperativas adheridas eran una minoría insignificante.

En el mapa 2, que registra las bodegas cooperativas existentes en 1933, puede apreciarse que casi una tercera parte de ellas formaban parte de entidades adheridas al IACSI y, significativamente, en las zonas de mayor implantación de la UR eran una proporción muy superior (aproximadamente la mitad). En estas zonas, las bodegas cooperativas seguían siendo pocas, es decir que se mantenía la desconexión entre el cooperativismo vitivinícola y el sindicalismo rabassaire de los años veinte que ya observábamos en el mapa 1.

\section{LOS CAMBIOS DE LOS AÑOS TREINTA}

La proclamación de la Segunda República en 1931 abrió grandes expectativas de cambios legislativos que facilitaran a los rabassaires el acceso a la propiedad de la tierra o, al menos, la mejora de su situación contractual. El Gobierno autónomo catalán estaba en manos de un nuevo partido político (ERC), que era favorable a los intereses de los rabassaires y que atendió sus demandas con la aprobación en el Parlamento catalán de la Ley de Contratos de Cultivo (1934). Sin embargo, su aprobación se produjo en un contexto de alta conflictividad social entre rabassaires y propietarios, que desembocó en una crisis política al ser impugnada y anulada dicha ley por el Tribunal de Garantías Constitucionales. Los acontecimientos del 6 de octubre de 1934, en los que los rabassaires tuvieron una participación destacada, no fueron en absoluto ajenos al desenlace de esta ley y a la tensión social agraria existente entonces en Cataluña ${ }^{65}$.

La influencia de la UR en el debate político catalán durante la Segunda República se explica por el crecimiento excepcional del sindicato durante los

${ }^{65}$ Sobre la participación de los rabassaires en la revuelta de octubre de 1934, véase LÓPEZ ESTEVE, 2013. ARNABAT, 2014. POMÉS, 2014. Sobre la cuestión social agraria en Cataluña durante los años treinta, véase BALCELLS, 1968. CAMPS I ARBOIX, 1971. MAYAYO, 1995: 131-163. POMÉS, 1999, vol. 9: 167-169. PLANAS, 2006: 188-220; 2013: 275-348. BOSCH, 2015. DOMÈNECH y HERREROS, 71/4 (2018): 1322-1348. 
años treinta: si durante los años veinte la UR no había excedido los cinco mil adheridos y cincuenta secciones locales, en abril de 1932 ya superaba los veinte mil miembros agrupados en 173 secciones locales, y en 1935 los afiliados ya eran más de cuarenta mil en 350 secciones y sindicatos adheridos ${ }^{66}$. Su vicepresidente afirmaba que la verdadera UR «comienza en $1931 »^{67}$.

Paralelamente a esta expansión, la UR no sólo redobló sus esfuerzos para conseguir un cambio en las condiciones contractuales del agro catalán, sino que también apostó más decididamente por el cooperativismo agrario y desarrolló su propia acción cooperativa ${ }^{68}$. La preocupación por la acción cooperativa no era ninguna novedad. En la asamblea general de la UR de enero de 1924 ya se debatió una propuesta para organizar, por medio de cooperativas, el intercambio de productos agrícolas entre las distintas regiones productoras, suprimiendo el intermediario o negociante. El propio Lluís Companys, que entonces era su dirigente más importante, defendió la iniciativa, argumentando que, sin abdicar del carácter social del movimiento rabassaire, creía conveniente fomentar el crédito agrario, las cajas rurales, las cooperativas de producción y todo lo que contribuyera a una mejora general y «a la creación de intereses que den apoyo a la organización» ${ }^{69}$. Su argumento, pues, se basaba principalmente en la necesidad de fortalecer el sindicato UR, entonces recién creado, de la misma forma que la UVC intentó reforzar su organización apoyándose en el cooperativismo vitivinícola.

Con este objetivo, en 1924 la UR se dotó de una sección cooperativa a través de la que podían operar las cooperativas agrícolas adheridas; pero estas eran pocas y hasta los años treinta la actividad de esta sección fue muy modesta. Además, aunque la UR tenía su implantación más importante en las áreas vitícolas, su actividad cooperativa se concentró principalmente en el sector de las patatas y las hortalizas, y no en la del vino. No fue hasta finales de los años veinte cuando algunas secciones de la UR comenzaron a operar como cooperativas, y en los años treinta muchos sindicatos rabassaires ya se crearon como cooperativas agrícolas. Finalmente, en 1935, la UR tomó la decisión de convertir todas sus secciones o sociedades adheridas en cooperativas agrícolas. Con ello, según el presidente de la UR, estaba creando «por primera vez en Cataluña, un movimiento cooperativo agrícola que responde a las exigencias de la más depurada doctrina cooperativista $\rangle^{70}$.

En estas declaraciones, el presidente de la UR, Josep Calvet, aludía veladamente a la USAC, a la que la UR pretendía enfrentarse en su propio terreno, el

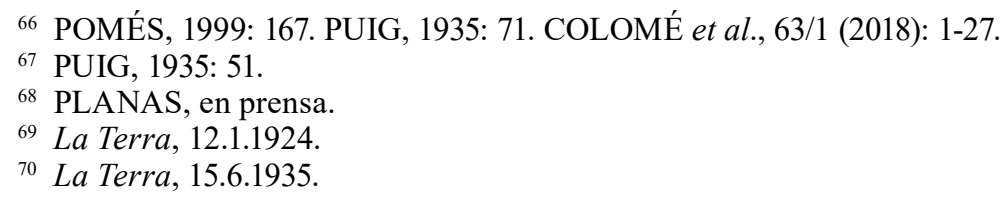


de la acción cooperativa. La USAC se había constituído el 12 de julio de 1931, en un acto en Barcelona que contó con la presencia del presidente de la Generalitat, Francesc Macià, y al que asistieron representantes de «la inmensa mayoría de los agricultores organizados de Cataluña, o sea de 800 sindicatos, más de $500 \gg{ }^{71}$. Esta nueva asociación pretendía agrupar a todos los sindicatos y cooperativas agrícolas de Cataluña, y a su primera asamblea general, celebrada en abril de 1932, asistieron representantes de 520 sindicatos adheridos, que representaban a unos 60.000 agricultores $^{72}$. La USAC se organizaba en comités representativos de las distintas orientaciones agropecuarias: 1) Comité de Cereales; 2) Comité de Frutas y Verduras; 3) Comité del Aceite; 4) Comité de Ganadería; 5) Comité de Productos Hortícolas; 6) Comité del Vino. Estos comités celebraban una asamblea anual, en la que se aprobaban unas conclusiones que, una vez examinadas por la asamblea general de la USAC para su ratificación o modificación, eran trasladadas a las esferas del Gobierno ${ }^{73}$.

De este modo, la USAC ampliaba a los distintos sectores agrícolas la actividad que ya llevaba a cabo la UVC, que fue una de las entidades fundadoras y que se convirtió en el Comité de la Producción Vitícola de la USAC, «constituyendo una sola entidad $\rangle^{74}$. De acuerdo con su preeminencia, la presidencia de la USAC recayó en un primer momento en el presidente honorario de la UVC, Francesc Santacana. En 1933 le sucedería Carles Jordà, que también procedía de la UVC (fue presidente del consejo comarcal de la UVC del Empordà) y que impulsó en esta comarca la creación de las bodegas cooperativas de Espolla y de Ricardell, así como también la creación del Sindicato Comarcal del Empordà, con destilería cooperativa, y cuya presidencia ocupó sin interrupción ${ }^{75}$.

Como la UVC, la USAC evitó posicionarse en relación con la cuestión social agraria, refugiándose en un supuesto apoliticismo de sus «asambleas de productores $\rangle^{76}$ y limitándose a formular propuestas de orden simplemente económico:

Perquè entenem que abans de tota cosa hi ha una producció agrícola a conservar i a defensar, creiem que fins ara s'ha donat massa importància a un problema, efectivament existent, però d'una urgència relativa com és el de la possessió de la terra, i s'ha negligit la qüestió essencial d'afrontar en tota la seva magnitud el paorós conflicte permanent de la col·locació i de la valorització dels productes de la terra ${ }^{77}$.

${ }^{71}$ Agricultura i Ramaderia, 15.7.1931.

72 Agricultura i Ramaderia, abril de 1932.

73 RIBAS, 1974: 52-53.

${ }^{74}$ El Viticultor, Barcelona, agosto de 1931.

75 Carles Jordà también fundó el Sindicato Oleícola Garrotxa-Empordà (1929), que fue una de las entidades promotoras de la USAC, junto con la UVC, el Sindicato Agrícola de Cervera, la Federación de Sindicatos Agrícolas del Litoral, el Sindicato «La Oliva Arbequina», la Federación Agrícola de la Conca de Barberà y las bodegas cooperativas de Vila-rodona y Espolla.

${ }^{76}$ F. Santacana, «La darrera Assemblea de productors», Agricultura i Ramaderia, julio de 1933.

77 Pagesia, 27.1.1934. Citado en RIBAS, 1974: 124. 
La UR reclamó desde un primer momento que la USAC no se preocupara solamente de la producción y la venta de los productos de la tierra, «sino también de la legislación agraria $\rangle^{78}$. Pero esta petición fue inútil. El posicionamiento de la USAC fue denunciado repetidamente por la UR como una falsa neutralidad entre las posiciones de los propietarios (IACSI) y de los rabassaires (UR); se acusó a la USAC de separar a los agricultores del proceso político iniciado con el nuevo régimen republicano e, incluso, de buscar la destrucción del sindicato rabassaire ${ }^{79}$.

Este enfrentamiento con la USAC también ayuda a explicar la apuesta de la UR por el cooperativismo. Según el presidente de la UR, Josep Calvet, que con anterioridad había presidido una cooperativa agrícola, para que estas entidades realizaran una acción eficaz tenían que estar claramente al servicio de un grupo social. La UR siempre se opuso a la pretensión de eliminar la lucha de clases del ámbito de actuación de las cooperativas agrícolas y denunciaba que la supuesta neutralidad e independencia política de estas entidades no era más que una artimaña para «engañar a los bobos» y continuar defendiendo los privilegios de la clase propietaria ${ }^{80}$. La misión de la UR consistía, pues, en organizar el cooperativismo fuera de la tutela de los propietarios rurales ${ }^{81}$.

En los años treinta la UR se veía con fuerzas para esta labor, no sólo porque era una asociación mucho más grande y bien organizada, sino porque contaba con el apoyo de la Consejería de Agricultura de la Generalitat que, desde enero de 1934, estaba dirigida por el socialista Joan Comorera. La involución política que se produjo después de octubre de 1934 no hizo más que afianzar esta orientación, al desvanecer las esperanzas de un cambio legislativo que mejorara las condiciones contractuales de los rabassaires. La apuesta por el cooperativismo se enmarcaba en una mayor intervención de la UR en la esfera económica, que ahora - como se manifestaba en su órgano de prensa - se consideraba tanto o más necesaria que la lucha social:

No n'hi ha prou amb lluitar per la terra. Cal lluitar també per obtenir una recompensa justa i equitable del treball del conreador mitjançant la valorització dels seus productes, sense la qual la possessió de la seva totalitat no tindria cap efecte ${ }^{82}$.

Esta intervención en la esfera económica la proyectaban no sólo en el ámbito de las compras, que ya realizaban en alguna medida desde los años veinte, sino en el de las ventas, «que es el ámbito decisivo y único que puede justificar completamente la verdadera actuación sindical» ${ }^{83}$.

\footnotetext{
${ }^{78}$ El Vinyater, Barcelona, 6.12.1930.

${ }^{79}$ MAYAYO, 1995: 124.

${ }^{80}$ La Terra, 15.9.1935.

${ }^{81}$ La Terra, 30.11.1935.

${ }^{82}$ La Terra, 15.2.1935.

${ }^{83}$ La Terra, 30.11.1935.
} 
Desde el movimiento cooperativo, ya habían surgido con anterioridad algunas iniciativas para comercializar conjuntamente el vino de las bodegas cooperativas, que no llegaron a funcionar. Por ejemplo, en 1920, como resultado de una reunión en Tarragona que contó con representantes de la mayoría de bodegas cooperativas existentes, se nombró una comisión para organizar «una Sección Comercial de Ventas como solución definitiva» ${ }^{84}$. En 1932 surgió otra iniciativa similar: la creación de una «Cooperativa Central de Cellers de Catalunya» con el objetivo de «conseguir la venta directa del productor al consumidor, garantizando la pureza del vino y persiguiendo su adulteración $\rangle^{85}$. Las bodegas cooperativas adheridas iniciaron gestiones con algunas cooperativas de consumo españolas y extranjeras para efectuar la venta directa; pero sus resultados también fueron infructuosos.

En 1935, la UR también lanzó un proyecto para la instalación de unos almacenes centrales para elaborar y expedir el vino de sus bodegas cooperativas adheridas, accediendo directamente a los mercados consumidores sin intermediarios. La iniciativa se planteó por primera vez en marzo de 1935, cuando se nombró una comisión para estudiar los problemas que planteaba a los rabassaires la crisis vinícola y buscar las soluciones apropiadas, prestando especial atención a las relaciones directas de los productores con los consumidores mediante la organización cooperativa ${ }^{86}$. No fue hasta el mes de octubre cuando se establecieron las «Bases para el funcionamiento de la Sección Vinícola», y en la asamblea del 3 de noviembre de 1935 se presentó el proyecto de creación del almacén central de preparación y expedición de vinos. El objetivo de esta Central Vinícola Cooperativa era eliminar intermediarios y aumentar la independencia de las bodegas cooperativas respecto del comercio privado.

Las bodegas cooperativas adheridas a esta sección de la UR tenían que aportar una cantidad de vino determinada, establecida según las demandas recibidas y la proporción de sus calidades, para la preparación de los vinos contratados. En los almacenes de la Central Vinícola Cooperativa, se agruparían los tipos de las diversas bodegas cooperativas para, mediante coupage, producir los tipos que requerían los mercados consumidores, tanto del interior como del extranjero. Con la Federación de Cooperativas de Cataluña se pretendía crear una empresa mixta para el suministro de vino a las cooperativas de consumo y, al mismo tiempo, conseguir para este vino la exención de impuestos municipales. En 1936, el periódico La Terra empezó a publicitar el proyecto con el lema «iConsumiu vi dels vostres propis companys!», que se dirigía especialmente a las cooperativas adheridas de regiones no vitícolas, con el objetivo

\footnotetext{
${ }^{84}$ Agricultura, 20.12.1920.

${ }^{85}$ Agricultura i Ramadera, 6.1932.

${ }^{86}$ La Terra, 15.4.1935.
}

Hispania, 2020, vol. LXXX, n. ${ }^{\circ}$ 264, enero-abril, págs. 201-229, ISSN: 0018-2141, e-ISSN: 1988-8368 https://doi.org/10.3989/hispania.2020.007 
de que, a través de la Central Vinícola Cooperativa, se aprovisionaran exclusivamente del vino producido en las bodegas cooperativas adheridas a la UR.

A las bodegas interesadas en el proyecto no se les exigía la adhesión previa a la UR; pero solamente eran aceptadas aquellas bodegas constituidas de acuerdo con la Ley de Sindicatos Agrícolas aprobada por el Parlamento de Cataluña ${ }^{87}$. Con ello se quería asegurar la igualdad de derechos de los miembros individuales de las cooperativas, que siempre había reivindicado la UR. Sin embargo, la mayoría de bodegas cooperativas no adaptaron sus reglamentos a la nueva ley, de modo que a finales de 1935 la Central Vinícola Cooperativa contaba solamente con la adhesión de las bodegas cooperativas de Porrera, Vila-rodona, les Cabanyes y Vilafranca del Penedès. Sabemos, además, que unos meses después la cooperativa de les Cabanyes se retiró del proyecto. Según el acuerdo tomado por la junta directiva del Sindicato Agrícola de les Cabanyes en junio de 1936, se renunciaba a participar en la Central Vinícola Cooperativa al entender que «no responde a los proyectos y necesidades de los sindicatos», como también habían hecho los demás ${ }^{88}$.

En definitiva, en un momento en que la orientación cooperativista de la UR se había afirmado claramente y en que la mayoría de cooperativas agrícolas ingresaban en la UR, como organización agraria más potente en Cataluña, las bodegas cooperativas seguían siéndole ajenas.

\section{ConClusión}

La crisis vinícola de comienzos del siglo XX dio lugar en Cataluña a una doble respuesta asociativa. En primer lugar, los viticultores se organizaron para protestar y reclamar la protección del Gobierno. Puesto que el incremento de las exportaciones era muy difícil en un contexto de sobreproducción estructural a nivel internacional, las demandas se concentraron en la regulación del mercado interior y, especialmente, en la persecución de los vinos artificiales que deprimían el precio del vino de uva. El cooperativismo vitivinícola fue la segunda respuesta asociativa. Sus objetivos eran la mejora de los procesos de elaboración del vino, el aprovechamiento de sus subproductos, la reducción de los costes de producción y la mejora de la posición de los viticultores en el proceso de comercialización del vino.

Ambas respuestas asociativas tenían como objetivo el aumento de los ingresos y del nivel de vida de los viticultores. Sus estrategias para conseguirlo eran distintas, pero se complementaban y en las dos vías se producían sinergias. Las

\footnotetext{
87 «Bases per al funcionament de la Secció Vinícola», base II (La Terra, 30.11.1935).

${ }^{88}$ Acta de la junta directiva del Sindicato Agrícola de les Cabanyes, 18.6.1936. Citada en SAUMELL, 2002: 220.
}

Hispania, 2020, vol. LXXX, n. ${ }^{\circ} 264$, enero-abril, págs. 201-229, ISSN: 0018-2141, e-ISSN: 1988-8368 https://doi.org/10.3989/hispania.2020.007 
cooperativas facilitaban la movilización de los viticultores y aumentaban su cohesión, reforzando las campañas en defensa de sus intereses ante el Gobierno. El éxito de estas campañas también beneficiaba a los cooperativistas, en la medida que contribuían al sostenimiento de los precios de venta del vino. Ambas formas de acción colectiva necesitaban de la colaboración interclasista de grandes y pequeños viticultores, y la mayoría de dirigentes de la UVC eran propietarios que procedían del mundo de las cooperativas.

El sindicalismo rabassaire era, en cambio, un movimiento de clase que perseguía el aumento del nivel de vida de los cultivadores vitícolas a través de cambios legislativos que permitieran una redistribución de la renta de la tierra. Muchos de sus dirigentes también procedían del ámbito del cooperativismo y eran sensibles a la crisis de los precios del vino, pero hasta los años treinta priorizaron la cuestión contractual, desconfiando de una acción conjunta de propietarios y cultivadores que desdibujaba la lucha de clases. Las bodegas cooperativas eran muy difíciles de crear de forma autónoma por parte de los rabassaires y, si estas contaban con la participación de los propietarios, no se ajustaban al alineamiento de clase que los rabassaires ambicionaban para el asociacionismo agrario. Además, el apoyo que las bodegas cooperativas recibían del Gobierno de la Mancomunitat, al que consideraban un adversario, también contribuyó a desvincularlos del cooperativismo vitivinícola.

En los años treinta, con la expansión y el fortalecimiento del sindicalismo rabassaire, la UR apostó decididamente por el cooperativismo, compitiendo directamente con la UVC y la USAC. Después del 6 de octubre de 1934, la represión limitó la lucha por las mejoras contractuales e, indirectamente, reforzó la apuesta cooperativista. Fue entonces cuando, ya como federación de cooperativas, la UR llegó a convertirse en el eje dominante del cooperativismo agrario catalán. Sin embargo, este momento llegó muy poco antes del estallido de la guerra civil y para entonces la mayor parte de las bodegas cooperativas tenía su propia dinámica. No podemos saber si el proyecto de comercialización conjunta del vino, que quedó abortado por la guerra, habría podido cambiarla.

\section{Bibliografía}

Arnabat, Ramon, «Mobilització i revolta social: el Penedès durant els fets d'octubre de 1934», en Arnau Gonzàlez Vilalta, Manel López Esteve y Enric Ucelay-Da Cal (eds.), 6 d'octubre. La desfeta de la revolució catalanista de 1934, Barcelona, Editorial Base, 2014: 251-278.

Balcells, Albert, El problema agrari a Catalunya (1890-1936): la qüestió rabassaire, Barcelona, Nova Terra, 1968.

Bosch, Pere, La lluita per la terra. Solidaritats pageses i conflictivitat rural a la regió de Girona (1931-1936), Girona, Documenta Universitaria, 2015. 
Camps i Arboix, Joaquim de, Història de la Llei de Contractes de Conreu, Barcelona, Rafael Dalmau, 1971.

Carmona, Juan y Simpson, James, «The "Rabassa Morta" in Catalan viticulture: the rise and decline of a long term sharecropping contract, 1670s-1920s», The Journal of Economic History, 59/2 (Cambridge, 1999a): 290-315.

Carmona, Juan y Simpson, James, «A l'entorn de la qüestió agrària catalana: el contracte de rabassa morta i els canvis en la viticultura, 1890-1929», Recerques, 38 (Barcelona, 1999b): 105-124.

Caupert, Maurice, Essai su la C.G.V., ses origines, son organisation, son oeuvre, Montpellier, Imprimerie de 'L'Economiste Meridional', 1921.

Colomé, Josep, «L'ofensiva dels propietaris contra el contracte de rabassa morta», Recerques, 67 (Barcelona, 2013): 115-140.

Colomé, Josep, García, Ricard, Planas, Jordi y Valls-Junyent, Francesc, «Les cicles de l'économie viticole en Catalogne. L'évolution du prix du vin entre 1680 et 1935», Annales du Midi. Revue de la France Méridionale, 281 (Toulouse, 2013): 29-55.

Colomé, Josep, Planas, Jordi, Soler-Becerro, Raimon y Valls-Junyent, Francesc, «The Rabassaire Struggle: Long-term Analysis of a Social and Political Movement», International Review of Social History, 63/1 (Amsterdam, 2018): 1-27.

Domènech, Jordi y Herreros, Francisco, «Land reform and conflict before the Civil War: landowner response to tenancy reform in 1930s Catalonia», Economic History Review, 71/4 (Londres, 2018): 1322-1348.

Fernández, Eva, «El fracaso del lobby viticultor en España frente al objetivo industrializador del Estado, 1920-1936», Historia Agraria, 45 (Murcia, 2008): 113-141.

Fernández, Eva y Simpson, James, «Product quality or market regulation? Explaining the slow growth of Europe's wine cooperatives, 1880-1980», Economic History Review, 70/1 (Londres, 2017): 122-142.

Fuguet, Joan y Mayayo, Andreu (eds.): El primer celler cooperatiu de Catalunya. Centenari de la Societat de Barberà de la Conca (1894-1994), Barcelona, Generalitat de Catalunya, 1994.

Garrido, Samuel, «Sharecropping was sometimes efficient: sharecropping with compensation for improvements in European viticulture», Economic History Review, 70/3 (Londres, 2017a): 977-1003.

Garrido, Samuel, «¿Desnaturalizados rabassers? La rabassa morta catalana antes de la filoxera», Ayer, 107 (Madrid, 2017b): 155-182.

Garrido, Samuel, «El fruto de la inseguridad. Vino, contrato óptimo y derechos de propiedad en Cataluña (1898-1935)», Revista de Historia Económica, 35/3 (Madrid, 2017c): 415-443.

Garrido, Samuel, «Cooperatives, opportunism and quality product: Why the early Spanish cooperative wineries produced ordinary wine», Business History (Londres, 2019). https://doi.org/10.1080/00076791.2019.1685504.

Gavaldà, Antoni, L'associacionisme agrari a Catalunya. (El model de la Societat Agrícola de Valls, 1888-1988), Valls, IEV, 1989, 2 vols.

Gavaldà, Antoni y Santesmases, Josep, Història econòmico-social de les cooperatives agricoles de Nulles (1917-1992), Valls, IEV, 1993. 
Gavignaud-Fontaine, Geneviève, «Les combats du Midi viticole ou le pragmatisme des gauches vigneronnes», en Caractères historiques du vignoble en Languedoc et Roussillon, Montpellier, Presses de l'université Paul-Valéry, 1997: 321-361.

Giralt, Emili, «El Conflicto 'Rabassaire' y la Cuestión Agraria en Cataluña hasta 1936», Revista de Trabajo, 3 (Madrid, 1964): 51-72.

Hansen, Edward C., "The State and Land Tenure Conflicts in Rural Catalonia», Anthropological Quarterly, 42/3 (Washington D.C., 1969): 214-243.

Lachiver, Marcel, Vins, vignes et vignerons. Histoire du vignoble français, París, Fayard, 1988.

López Esteve, Manel, Els fets del 6 d'octubre de 1934, Barcelona, Editorial Base, 2013. López Estudillo, Antonio, «Federalismo, campesinado y métodos de restablecer el control político en la Restauración», en Conxita Mir (ed.), Actituds polítiques $i$ control social a la Catalunya de la Restauració (1875-1923), Lleida, Virgili \& Pagès, 1989: 191-207.

Mayayo, Andreu, «El naixement del moviment coooperatiu a la Conca de Barberà», Estudis d'Història Agrària, 5 (Barcelona, 1985): 133-155.

Mayayo, Andreu, «El cooperativisme agrari: un moviment dual», en Conxita Mir (ed.), Actituds politiques i control social a la Catalunya de la Restauració (18751923), Lleida, Virgili \& Pagès, 1989: 209-232.

Mayayo, Andreu, De pagesos a ciutadans. Cent anys de sindicalisme i cooperativisme agraris a Catalunya, 1893-1994, Catarroja/Barcelona, Afers, 1995.

Moreno, Belén, «La rabassa morta, sus actores y la defensa del carácter enfitéutico, 1740-1850», Historia Agraria, 78 (Murcia, 2019): 7-36.

Muñiz, Lorenzo, La Acción Social Agraria en España. Memoria Estadística de las Entidades Agrícolas y Pecuarias en $1^{\circ}$ de Diciembre de 1924, Madrid, Ministerio de Fomento, Dirección General de Agricultura y Montes/Establecimiento Tipográfico Nieto y Compañía, 1924.

Pan-Montojo, Juan, La bodega del mundo. La vid y el vino en España (1800-1936), Madrid, Alianza Editorial, 1994.

Pan-Montojo, Juan, «Las vitiviniculturas europeas: de la primera a la segunda globalización», Mundo Agrario [en línea], 9/18 (Buenos Aires, 2009).

Pinilla, Vicente y Ayuda, María-Isabel, «The political economy of the wine trade : Spanish exports and the international market, 1890-1935», European Review of Economic History, 6 (Oxford, 2002): 51-85.

Planas, Jordi, Els propietaris i l'associacionisme agrari a Catalunya (1890-1936), Girona, Documenta Universitaria, 2006.

Planas, Jordi, Viticultura i cooperativisme. La comarca d'Igualada, 1890-1939, Barcelona, PAM, 2013.

Planas, Jordi, «Els inicis del cooperativisme vitivinícola a Catalunya», en Josep Colomé, Jordi Planas y Francesc Valls-Junyent (eds.), Vinyes, vins $i$ cooperativisme vitivinícola a Catalunya, Barcelona, PAM, 2015: 369-401.

Planas, Jordi, «The emergence of winemaking cooperatives in Catalonia», Business History, 58/2 (Londres, 2016): 264-282.

Planas, Jordi, «State intervention in wine markets in the early twentieth century: Why was it so different in France and Spain?», Revista de Historia Económica, 35/2 (Madrid, 2017): 175-206. 
Planas, Jordi, «La Unión de Rabassaires y el cooperativismo», Ayer (Madrid, en prensa). Planas, Jordi y Vallès, Josep M., «L'Espluga de Francolí, model del cooperativisme vitivinícola català», en Josep Colomé, Jordi Planas y Francesc Valls-Junyent (eds.), Vinyes, vins $i$ cooperativisme vitivinicola a Catalunya, Barcelona, PAM, 2015: 437-471.

Planas, Jordi y Valls-Junyent, Francesc, «¿Por qué fracasaban las cooperativas agrícolas? Una respuesta a partir del análisis de un núcleo de la Cataluña rabassaire», Investigaciones de Historia Económica, 7/2 (Madrid, 2011): 310-321.

Pomés, Jordi, «La Unió de Rabassaires», en Borja de Riquer (ed.), Història, Política, Societat i Cultura dels Països Catalans, Barcelona, Enciclopèdia Catalana, 1999, vol. 9: 167-169.

Pomés, Jordi, La Unió de Rabassaires. Lluís Companys i el republicanisme, el cooperativisme i el sindicalisme pagès a la Catalunya dels anys vint, Barcelona, PAM, 2000.

Pomés, Jordi, «La Unió de Rabassaires i la insurrecció d’Octubre», en Arnau Gonzàlez Vilalta, Manel López Esteve y Enric Ucelay-Da Cal (eds.), 6 d'octubre. La desfeta de la revolució catalanista de 1934, Barcelona, Editorial Base, 2014: 335350.

Puig, Nònit, Què és la Unió de Rabassaires, Barcelona, Nagsa, 1935.

Pujol, Josep, «La crisis de sobreproducción en el sector vitivinícola catalán, 18921935», en Ramon Garrabou, Carlos Barciela y José Ignacio Jiménez Blanco (eds.), Historia Agraria de la España Contemporánea, Barcelona, Crítica, 1986, vol. 3: 317-346.

Ribas, Montserrat, La Unión de Sindicatos Agrícolas de Cataluña (U.S.A.), tesis de licenciatura, Universitat de Barcelona, 1974.

Roche-Agussol, Maurice, Le rôle économique des associations agricoles. Une expérience de syndicalisme agricole ( $\mathrm{La}$ C.G.V.), Montpellier, Imprimerie Roumégous et Déhan, 1924.

Santesmases, Josep, El cooperativisme agrari a Vila-rodona (1893-1939). Un exemple d'estructuració econòmica, social i política en la Catalunya vitivinícola, Vila-rodona, Centre d'Estudis del Gaià, 1996.

Saumell, Antoni, Crisi vinícola, renovació tecnológica i cooperativisme: el Sindicat Agrícola del Vendrell i els cellers cooperatius del Penedès del primer terç del segle XX, tesis doctoral, Universitat Pompeu Fabra, 1998.

Saumell, Antoni, Viticultura i associacionisme a Catalunya. Els cellers cooperatius del Penedès (1900-1936), Tarragona, Diputació de Tarragona, 2002.

Saumell, Antoni, «El cooperativisme vitivinícola al Penedès durant el segle XX», en Josep Colomé (coord.), De l'aiguardent al cava. El procés d'especialització vitivinícola a les comarques del Penedès-Garraf, Vilafranca del Penedès, El 3 de Vuit/ Nadal Editor, 2003: 279-298.

Simpson, James, «Cooperation and Cooperatives in Southern European Wine Production», Advances in Agricultural Economic History, 1 (Londres, 2000): 95-126.

Simpson, James, Creating Wine. The Emergence of a World Industry, 1840-1914, Princeton, Princeton University Press, 2011. 
Soler-Becerro, Raimon, Viticultura, desigualtat $i$ conflicte agrari. La lluita per la terra a la Catalunya vitícola, 1900-1936, Tarragona, Publicacions URV/VINSEUM, 2019.

Soler-Becerro, Raimon, «El cooperativisme rabassaire al Penedès durant el primer terç del segle XX», Estudis d'Història Agrària (Barcelona, en prensa).

Troyano, Joan, «100 anys d'associacionisme agrari a Sant Cugat del Vallès (18961996)», Gausac, 9 (Sant Cugat del Vallès, 1996): 79-100.

Recibido: 27/09/2018

Aceptado: 09/09/2019 